\title{
MECHANICAL AND TRIBOLOGICAL BEHAVIOR OF LUFFA FIBER REINFORCED EPOXY COMPOSITE
}

\author{
M. SUBBIAH ${ }^{1}$ \& DR. A. SAJITHA BANU ${ }^{2}$ \\ ${ }^{I}$ Assistant Professor, Department of Mechanical Engineering PSNA College of Engineering \& Technology,
} Dindigul, Tamil Nadu, India

${ }^{2}$ Assosiate Professor, Department of Physics PSNA College of Engineering \& Technology, Dindigul, Tamil Nadu, India

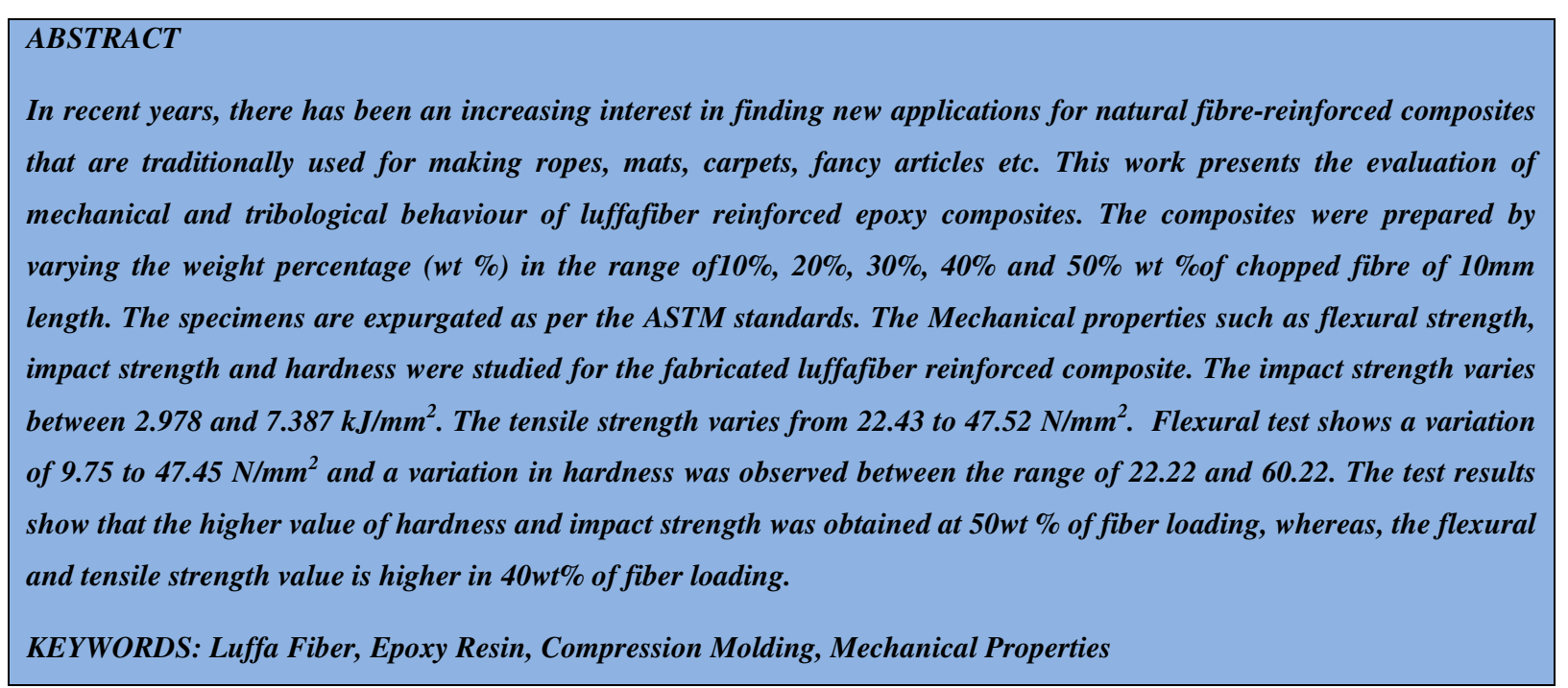

Received: Jun 08, 2020; Accepted: Jun 28, 2020; Published: Sep 19, 2020; Paper Id.: IJMPERDJUN20201341

\section{INTRODUCTION}

Material selection is the very basic criteria for all design and applications of the product. Also the increase in environmental consciousness leads to the need for the development of eco-friendly materials. Hence there arise a demand for fiber based composite materials due to its low cost, renewability, biodegradability and sustainability. Natural fibres have been used to reinforce materials for many years. Currently they have been employed in combination with plastics. Many types of natural fibres including flax, hemp, jute, sisal and banana have been studied for use in plastics. Compared to glass fibres, natural fibres have many advantages, low density, low cost and they are recyclable and biodegradable. The use of natural fiber reduces weight by $10 \%$ and lowers the energy needed for production by $80 \%$, while the cost of the component is $5 \%$ lower than the comparable fiber glassreinforced component. Luffafiber is one such natural fiber which has numerous advantages like low cost, highly abundant and relatively good mechanical properties. In the production of cords and clothing, fibers from luffa have been widely used. This novel luffa fiber is also used in, construction, automotive interior linings and packaging etc. For example, vehicle interior parts such as door trim panels made from natural fiber-polypropylene (PP) and exterior parts such as engine and transmission covers from natural fiber-polyester resins are used. 


\section{EXPERIMENTAL PROCEDURES}

\section{Materials}

Reinforcement resources luffafibers (cucurbitaceae) were procured from the farm field. The matrix material epoxy (103) and hardener (HY951) were purchased from Leo enterprises, Nagercoil, India. Epoxy resin mixed with hardener in the ratio10:1.

\section{Specimen Preparation}

The specimens are equipped by different weight fraction. The mold was closed with cover plate, and hydraulic pressure machines were used for compression. The composites were fabricated in the form of a flat plate with a size of $180 * 160 * 3 \mathrm{~mm}$. The matrix solution was applied on the mold and fiber is spread over there in, air bubbles were removed carefully with a roller. Composite plates were prepared for various fiber weight percentage of 30, 40 and 50.

Table 1: Fiber Weight Percentage of the Composite Samples

\begin{tabular}{|c|c|c|c|}
\hline Specimen No & Resin wt \% & Fiber wt \% & Fiber Weight g \\
\hline 1 & 100 & 0 & 0 \\
\hline 2 & 90 & 100 & 12.56 \\
\hline 3 & 80 & 20 & 18.72 \\
\hline 4 & 70 & 30 & 28.50 \\
\hline 5 & 60 & 40 & 38.01 \\
\hline 6 & 50 & 50 & 47.52 \\
\hline
\end{tabular}

\section{Mechanical Testing}

\section{Impact Test}

The required dimensions of impact test specimens are prepared accordingly to the ASTM-A370 standard. The testing process is done by loading the specimen in the testing machine and allows the pendulum to hit until it fractures or breaks. The effect of strain rate on fracture and ductility of the material can be analysed by using the impact test.

Table 2: Experimental Impact Strength of the Composite Samples

\begin{tabular}{|c|c|c|c|c|}
\hline Sample No. & Samples & Trial 1 & Trial 2 & Average $\left(\mathrm{kJ} / \mathrm{mm}^{2}\right)$ \\
\hline S1 & $10 \%$ luffafiber $+90 \%$ Epoxy resin & 2.984 & 2.973 & 2.978 \\
\hline $\mathrm{S} 2$ & $20 \%$ luffafiber $+80 \%$ Epoxy resin & 3.587 & 3.987 & 3.787 \\
\hline S3 & $30 \%$ luffafiber $+70 \%$ Epoxy resin & 5.197 & 4.867 & 5.032 \\
\hline S4 & $40 \%$ luffafiber $+60 \%$ Epoxy resin & 4.816 & 6.561 & 5.688 \\
\hline S5 & $50 \%$ luffafiber $+50 \%$ Epoxy resin & 7.651 & 7.123 & 7.387 \\
\hline
\end{tabular}

\section{Tensile Test}

The Tensile test specimens are prepared according to the required dimension following the ASTM-D638 standard. During the testing process, the specimen must be elongated and get fractures or breaks. The effect of elongation rate on ductility fracture and of the material can be analysed by using the tensile testing machine. 
Table 3: Experimental Tensile Strength of the Composite Samples

\begin{tabular}{|c|c|c|c|c|}
\hline Sample No. & Samples & Trial 1 & Trial 2 & Average (N/mm $\mathbf{m}^{\mathbf{}}$ \\
\hline T1 & 10\% luffafiber + 90\% Epoxy resin & 22.51 & 22.36 & 22.43 \\
\hline T2 & 20\% luffafiber + 80\% Epoxy resin & 32.98 & 32.65 & 32.81 \\
\hline T3 & 30\% luffafiber + 70\% Epoxy resin & 42.30 & 46.57 & 44.43 \\
\hline T4 & 40\% luffafiber + 60\% Epoxy resin & 60.67 & 51.25 & 55.96 \\
\hline T5 & 50\% luffafiber + 50\% Epoxy resin & 57.86 & 37.19 & 47.52 \\
\hline
\end{tabular}

\section{Flexural Test}

The flexural test specimens are prepared as per the ASTM D790 standards and the test has been carried out using UTM. The specimen is subjected to 3-point flexural test which is the most common flexural test and it is used in this experiment for checking the bending strength of the composite materials. The test specimen is subjected to force until it fractures and breaks.

Table 4: Experimental Flexural Strength of the Composite Samples

\begin{tabular}{|c|c|c|c|c|}
\hline Sample No. & Samples & Trial 1 & Trial 2 & Average $\left(\mathbf{N} / \mathbf{m m}^{2}\right)$ \\
\hline F1 & 10\% luffafiber + 90\% Epoxy resin & 9.853 & 9.653 & 9.75 \\
\hline F2 & 20\% luffafiber + 80\% Epoxy resin & 12.365 & 12.364 & 12.36 \\
\hline F3 & 30\% luffafiber + 70\% Epoxy resin & 29.983 & 39.266 & 34.62 \\
\hline F4 & 40\% luffafiber + 60\% Epoxy resin & 49.65 & 45.25 & 47.45 \\
\hline F5 & 50\% luffafiber + 50\% Epoxy resin & 25.35 & 27.55 & 26.45 \\
\hline
\end{tabular}

\section{Hardness Test}

The Hardness of the test specimen was calculated using Shore'D Hardness Tester. The apparatus is a sharp ended tip type and the Hardness value was noted. The standard method used is ASTM D2240.

Table 5: Experimental Hardness Strength of the Composite Samples

\begin{tabular}{|c|c|c|c|c|c|c|}
\hline S. No. & Samples & Trial 1 & Trial 2 & Trial 3 & Trial 4 & Average \\
\hline H1 & 10\% luffafiber + 90\% Epoxy & 22.2 & 21.1 & 22.3 & 23.3 & 22.22 \\
\hline H2 & 20\% luffafiber + 80\% Epoxy & 33.25 & 33.24 & 34.21 & 33.21 & 33.47 \\
\hline H3 & 30\% luffafiber + 70\% Epoxy & 59.1 & 55.2 & 59.3 & 57.8 & 47.85 \\
\hline H4 & 40\% luffafiber + 60\% Epoxy & 56.6 & 60.3 & 56.7 & 58.2 & 57.95 \\
\hline H5 & 50\% luffafiber + 50\% Epoxy & 60.2 & 58.7 & 61.3 & 60.7 & 60.22 \\
\hline
\end{tabular}

\section{RESULTS AND DISCUSSION}

\section{Impact Test}

The energy observed in impact test goes increases with increase in fiber loading. The Impact strength comparison of the different combination of luffafiber reinforced composites is presented in Fig. 1. From the figure it can be observed that, the $50 \%$ luffafiber and 50\% epoxy resin composites are performing better than the other composite combinations tested which can hold the impact load of $0.189 \mathrm{~J} / \mathrm{mm}^{2}$. 


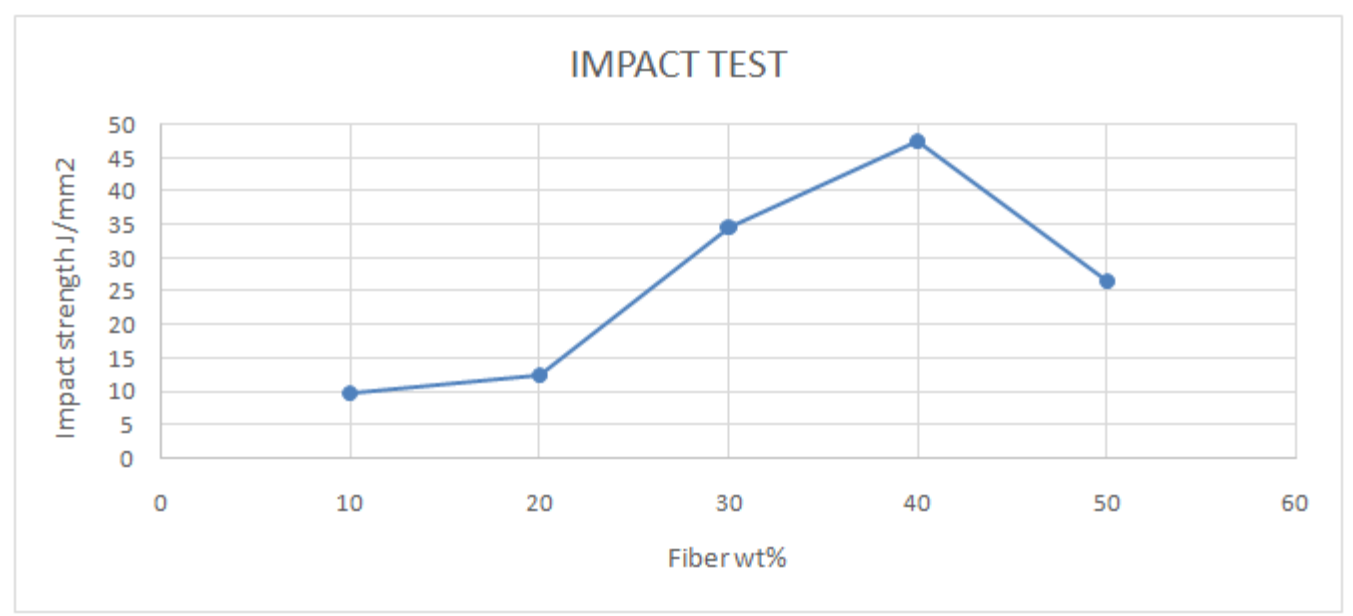

Figure 1: Impact Strength Comparison of the Luffafiber Composite Samples.

\section{Tensile Test}

The Tensile strength comparison of the different combination of luffafiber reinforced composites is presented in Figure 2.The results show that, $40 \%$ luffafiber and $60 \%$ epoxy resin composites are performing better than the other composite combinations fiber. The maximum tensile strength of $55.96 \mathrm{~N} / \mathrm{mm}^{2}$ is observed in the $40 \mathrm{wt} \%$ luffa fiber and $60 \%$ epoxy resin composites.

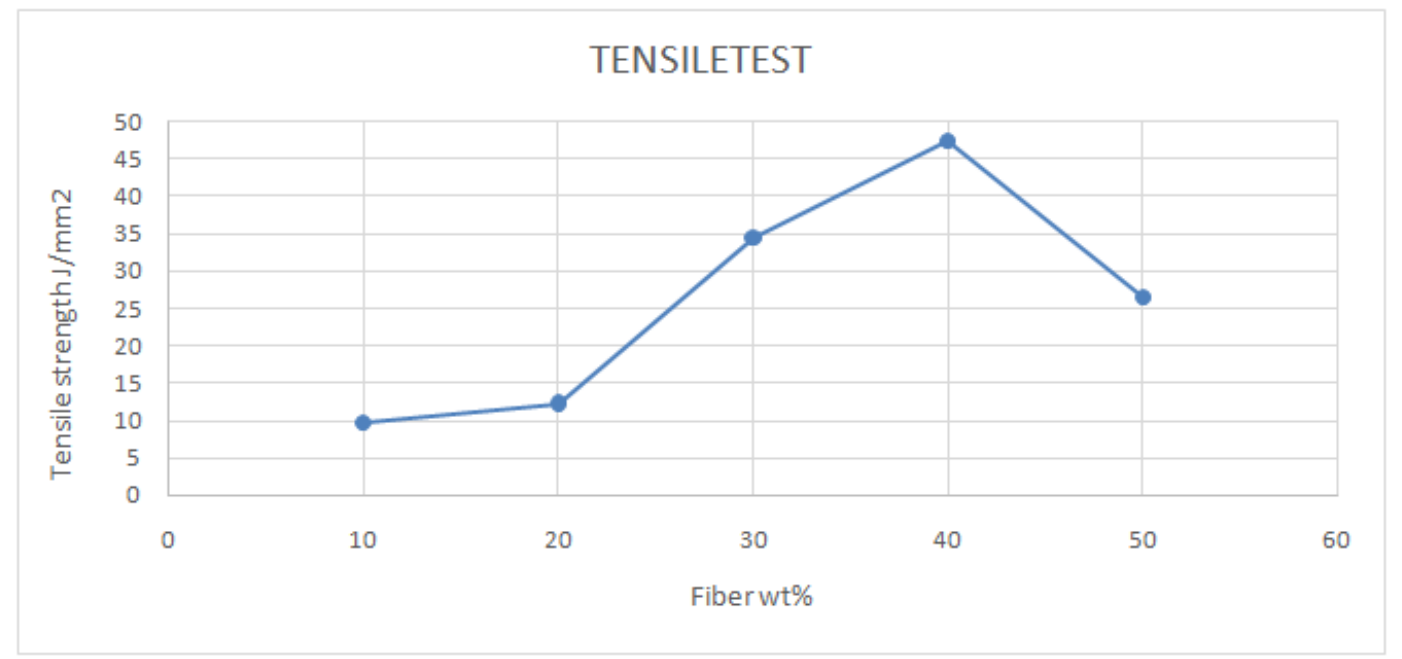

Figure 2: Tensile Strength Comparison of the Luffafiber Composite Samples.

\section{Hardness Test}

The Hardness strength comparison of the different combination of luffafiber reinforced composites is presented in Figure 3. The hardness test results shows that, the 50\% luffafiber and 50\% epoxy resin composites are performing better than the other composite combinations and has a maximum value of 60.22 . 


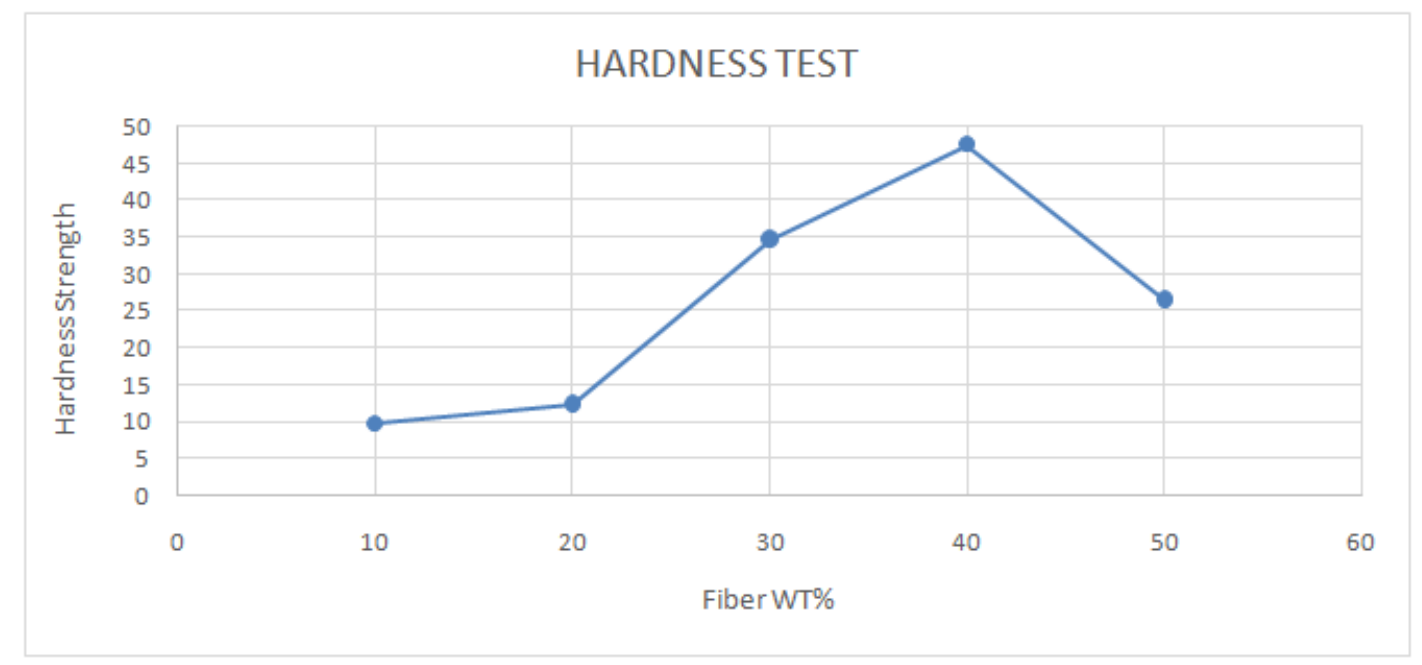

Figure 3: Hardness Strength Comparison of the Luffafiber Composite Samples.

\section{Flexural Test}

The flexural strength comparison of the different combinations of the luffafiber epoxy composites are presented in Fig.4.The result indicated that the $40 \%$ luffafiber and $60 \%$ epoxy resin composites are performing better than the other composite combinations tested which can withstand the flexural load of $47.45 \mathrm{~N} / \mathrm{mm}^{2}$.

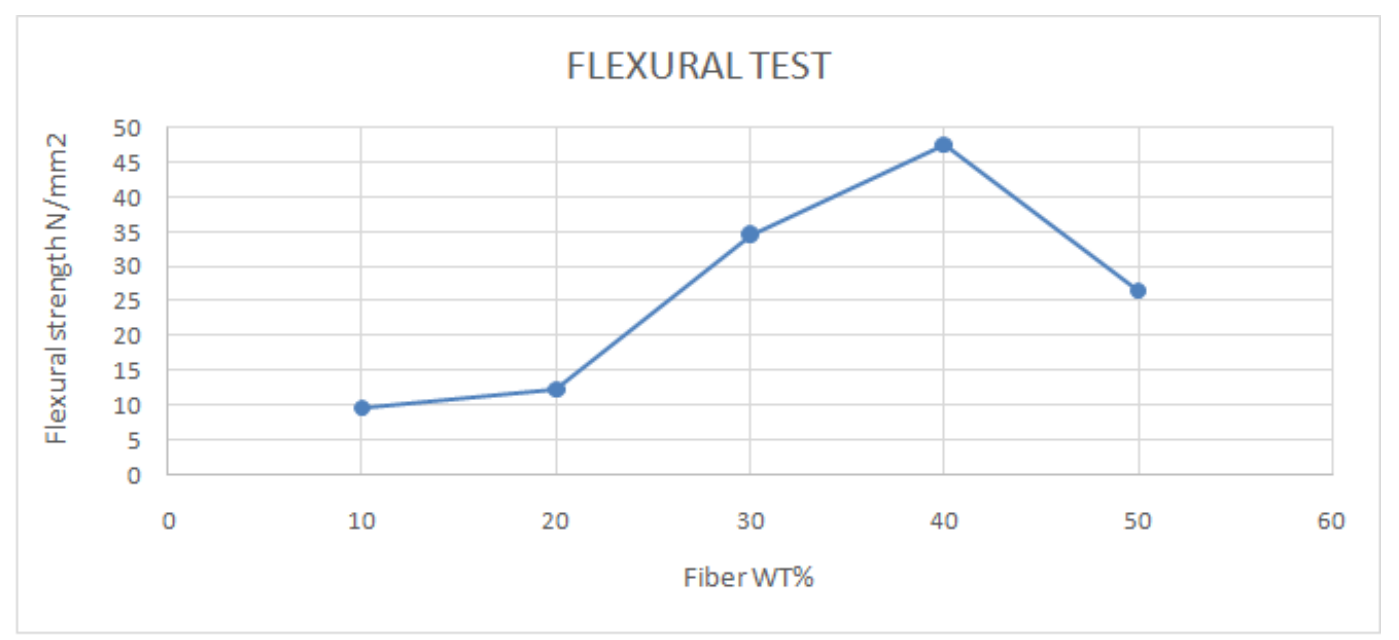

Figure 4: Flexural Strength Comparison of the Luffafiber Composite Samples.

\section{CONCULSIONS}

Luffafiber reinforced composites were fabricated and they were subjected to various mechanical testing. The results show that, the maximum hardness strength and the maximum impact strength is hold by the 50\% luffafiber and 50\% epoxy resin composites. Whereas, $40 \%$ luffafiber and 60\% epoxy resin composites has maximum tensile strength and maximum flexural strength. Thus from the experimental studies, it can be suggested that, the 50\% luffa fiber and 50\% epoxy resin composite materials can with stand the higher loads when compared to the other combinations. Hence this composite material can be used as alternate materials for conventional fiber reinforced composites. 


\section{REFERENCES}

1. William Jordana, Patrick Chestera Improving the Properties of Banana Fiber Reinforced Polymeric Composites by Treating the Fibers2000 (2017) 283-289.

2. JoãoBessaa, *, Joana Matosa, Carlos Motaa, Fernando Cunhaa, Isabel Araújob, LuísSilvab, ElizabetePinhob, RaúlFangueiroaInfluence of surface treatments on the mechanical properties of fibre reinforced thermoplastic composites 200 (2017) 465-471

3. R.Panneerdhassa, A.Gnanavelbabub*, K.RajkumarcMechanical Properties of LuffaFiber and Ground nut Reinforced Epoxy Polymer Hybrid Composites, ( 2014 ) 2042 - 2051

4. Karus M, Kaup M. Natural fibres in the European automotive industry. J Ind Luffa2002;7:117-29.

5. Maleque M. A., Belal F. Y., Sapuan S. M., Mechanical Properties Study of Pseudo-Stem LuffaFiber Reinforced Epoxy Composite, The Arabian Journal for Science and Engineering, 32 (2007), pp. 359-364.

6. Pothan L. A, Thomas S and Neelakantan, "Short LuffaFiberReinforcedPolyester Composites: Mechanical, Failure and Aging Characteristics”, Journal of Reinforced Plastics and Composites, 16(8), 1997, pp. 744-765.

7. Short Jute Fiber-Reinforced Polypropylene Composites: Effect of Compatibilizera. $k$. rana,1 a. mandal,1 b.c. mitra,1 r. jacobson,2 r. rowell,2 a. n. Banerjee Polymer Science, Vol69 (1998), 329-338.

8. Shankar P. S., Reddy K.T., Sekhar V. C., Mechanical Performance and Analysis of LuffaFiber Reinforced Epoxy Composites, International Journal of Recent Trends in Mechanical Engineering, Vol. 1, 2013, pp.1-10.

9. Laly A. Pothana, Zachariah Oommenb, and Thomas S, "Dynamic Mechanical Analysis of LuffaFiber Reinforced Polyester Composites”, Composites Science and Technology, 63(2), 2003, pp. 283-293.

10. S. Basavarajappa, K.V. Arun, J. Paulo Davim, "Effect of Filler Materials on Dry Sliding Wear Behavior of Polymer MatrixComposites - A TaguchiApproach”,Journal of Minerals \& Materials Characterization \& Engineering, Vol. 8, No.5,( 2009)pp 379-391.

11. S. Panthapulakkal, M. Sain,J. Appl. Poly. Sci. 103 (2007) 2432. 